\title{
Los límites establecidos al estado de conmoción interior en Colombia: un ejemplo a seguir en el contexto latinoamericano ${ }^{1}$
}

\author{
The Limits Established to the State of Internal Commotion in Colombia: An \\ Example to Follow in the Latin American Context
}

Mary Luz ToBón ToBóN 2

David MENDIETA 3

\begin{abstract}
Resumen: En este artículo se busca realizar una reflexión sobre el estado de conmoción interior en Colombia desde una perspectiva evolutiva, descriptiva y analítica, que nos permitirá comprender el test de proporcionalidad sobre los decretos legislativos y el rol protagónico ejercido por la Corte Constitucional colombiana en la defensa, promoción y respeto de los derechos humanos durante los estados de excepción en Colombia, fue esta una de las promesas cumplidas de los constituyentes de 1991, para quienes una de las mayores preocupaciones fue ponerle límites y garantías al uso abusivo del antiguo régimen del estado de sitio que vivió Colombia a la luz de la Constitución de 1886. Para desarrollar este planteamiento, el análisis se realizará en tres apartados: en el primero se abordará el uso abusivo del estado de sitio por parte de los distintos gobiernos de turno amparados en la vigencia del artículo 121 de la Constitución de 1886, se resalta que Colombia estuvo gobernada al amparo de un estado de sitio permanente hasta la promulgación de la Constitución de 1991. Luego, se estudiarán la naturaleza, los límites y presupuestos del estado de conmoción interior (antiguo régimen del estado de sitio) en el marco normativo de la Constitución de 1991 y, finalmente, se realizará un análisis sobre el uso que ha tenido la declaratoria del estado de conmoción interior desde 1991 hasta el año 2020, lo cual nos permitirá vislumbrar que este mecanismo ha caído en desuso en Colombia, por lo que

\footnotetext{
${ }^{1}$ El presente ensayo es un artículo de investigación, producto de un proyecto de investigación adscrito al Grupo de Investigación en Ciencias Sociojurídicas de la Facultad de Derecho de la Universidad Libre, Seccional Bogotá en asocio con el grupo de Investigaciones Jurídicas de la Facultad de Derecho de la Universidad de Medellín.

${ }^{2}$ Doctora en Derecho Constitucional de la Universidad Complutense de Madrid, Especialista en Derecho Administrativo, Abogada y Docente de la Facultad de Derecho de la Universidad Libre, Seccional Bogotá. Ciudad de Bogotá, Colombia. Correo electrónico: maryltobon@gmail.com.

${ }^{3}$ Doctor en Derecho Constitucional de la Universidad Complutense de Madrid. Profesor de tiempo completo de la Universidad de Medellín, miembro del Grupo de Investigaciones Jurídicas de la Facultad de Derecho de la Universidad de Medellín. Ciudad de Medellín, Colombia. Correo electrónico: davidmendietagonzalez@hotmail.com.
} 
el sistema de límites y controles del actual régimen del estado de excepción colombiano es un ejemplo a seguir por otros países en los que el uso de la excepción se ha convertido en la regla.

Palabras clave: Estado de sitio, conmoción interior, control de constitucionalidad, juicio de constitucionalidad, Colombia

\begin{abstract}
This article seeks to make a reflection on the state of internal commotion in Colombia, from an evolutionary, descriptive and analytical perspective, which will allow us to understand the proportionality test on legislative decrees and the leading role exercised by the Colombian Constitutional Court in the defense, promotion and respect for human rights during the states of exception in Colombia, being one of the promises fulfilled by the constituents of 1991, for whom one of the greatest concerns was to place limits and guarantees on the abusive use of the former regime of the state of site that Colombia lived in the light of the Constitution of 1886. To develop this approach, the analysis will be carried out in three sections: the first will address the abusive use of the state of siege by the various governments in force covered in force of article 121 of the 1886 Constitution, highlighting that Colombia was governed by of a permanent state of siege until the promulgation of the 1991 Constitution. Then, the nature, limits and budgets of the state of internal commotion (former regime of the state of siege) will be studied in the normative framework of the 1991 Constitution, and finally, an analysis will be carried out on the use that the declaration of the state of internal commotion has had from 1991 to the year 2020, which will allow us to glimpse that this mechanism has fallen into disuse in Colombia, so the system of limits and Controls of the current Colombian state of exception regime is an example to be followed by other countries where the use of the exception has become the rule.
\end{abstract}

Keywords: State of Siege, Internal Commotion, Constitutionality Control, Constitutionality Judgment, Colombia

\title{
1. Introducción
}

Para abordar el tema del estado de conmoción interior en Colombia, proponemos recordar las palabras de Pastor Pastrana, personaje de Gabriel García Márquez:

Quien después de vivir semanas interminables y meses alargados por la expectativa y el calor, se plantó con su redoblante en el centro de la plaza y leyó el bando de la decisión: se declaraba turbado el orden público, Tarrataplán, y el presidente de la República, Tarrataplán, disponía de las facultades extraordinarias, Tarrataplán, que le permitían asistir a los funerales de la Mamá Grande, Tarrataplán, rataplán, plan, plan4

Hoy se habla de la crisis de la democracia liberal en diferentes partes del mundo ${ }^{5}$, prueba de lo anterior es que, en el segundo semestre del año 2019, hubo movimientos sociales que manifestaron su inconformidad con los gobiernos de turno en países como Argentina, Colombia,

\footnotetext{
${ }^{4}$ García Márquez (1998).

${ }^{5}$ Mendieta (2019), p. 220.
} 
Ecuador, Perú, Bolivia y Chile. Además, en los últimos cuatro se declaró el estado de excepción. Interesante es el caso chileno que pretende iniciar un proceso para la obtención de una nueva Constitución y a quien la experiencia colombiana de establecerle límites al estado de conmoción interior podría servir de referente.

Colombia, al igual que los demás países latinoamericanos no pudo escapar al influjo que ejerció el uso del estado de excepción en Europa a partir de la Primera Guerra Mundial, por ello antes de la Constitución de 1991 hubo en el país andino un estado de sitio permanente, toda vez que este mecanismo fue usado de manera desproporcional por los distintos gobiernos de turno, para controlar las crisis que fueron generadas por la violencia política y el fenómeno del narcotráfico sin que tuviera éxito alguno. De hecho, se puede afirmar que en Colombia, durante la Constitución de 1886, la "anormalidad" se convirtió en la "regla general", con la consecuencia nefasta de que su utilización permitió la militarización de la sociedad y la vulneración de los derechos y las libertades fundamentales de los ciudadanos.

No obstante, y a pesar del uso desmedido de los poderes excepcionales por parte del Ejecutivo, los actos violentos de distintos actores armados siguieron manchando con sangre la realidad colombiana, y el Estado se quedó corto para enfrentar las amenazas constantes sobre los ciudadanos. Fue esta una gran lección para la Corte Constitucional colombiana, quien, a partir de la promulgación de la Constitución Política de 1991, paulatinamente empezó a desarrollar la teoría de que los problemas anacrónicos y estructurales del Estado colombiano no podían ser resueltos con el uso del estado de conmoción interior, o también llamado en la Constitución de 1886, estado de sitio, sino que requerían medidas permanentes, y no excepcionales o transitorias. Precisamente, fue esta una de las razones más importantes para construir un test de proporcionalidad en sentido estricto, que le permitiera ejercer de manera efectiva el control constitucional de los decretos legislativos expedidos durante los estados de excepción, colocando los derechos humanos y las libertades fundamentales de los colombianos como una barrera infranqueable para el Ejecutivo, demostrándole al pueblo colombiano que ante el viejo dilema "seguridad o libertad", hemos acogido en nuestro Pacto Constitucional la libertad, privilegiando los derechos y las libertades ciudadanas por encima de las razones de Estado y esto puede ser una gran enseñanza para toda América Latina, tan proclive, tal y como lo 
muestran hechos recientes, al uso y abuso de los poderes excepcionales para enfrentar situaciones de crisis ${ }^{6}$.

Así, una de las más graves preocupaciones que vivió el constituyente colombiano en 1991, y que giró en torno a la necesidad de ponerle un coto a los poderes desmedidos del estado de excepción, con respecto al estado de conmoción interior en la actualidad es una promesa cumplida, porque a la luz de la Constitución de 1991, la declaratoria de conmoción interior ha caído en desuso, tornándose en un mecanismo ineficaz para el poder Ejecutivo, tal como se demuestra en la tabla que hemos titulado Uso de los estados de conmoción interior en Colombia 1991-2020 (que encontrará más adelante) porque la última declaratoria del estado de conmoción interior declarada constitucional, fue hecha en el año 2002 durante el gobierno de Álvaro Uribe Vélez (2002-2010), mediante el Decreto 1837 de 2002, con el fin de contrarrestar el aumento de las acciones terroristas por parte de los grupos armados en las zonas rurales del país ${ }^{7}$. Por ello, y a pesar de que este decreto fue declarado exequible en la Sentencia C-802 de $2002^{8}$, es en este fallo donde la Corte Constitucional estableció el juicio de constitucionalidad que debía llevarse a cabo para poder realizar efectivamente el control constitucional de los decretos legislativos.

En este contexto, queda claro que la Constitución de 1991 y su lectura por parte de la Corte Constitucional, logran cumplir lo prometido en los debates que se dieron en la Asamblea Nacional Constituyente sobre la necesidad de ponerle límites y controles al uso desmedido del antiguo régimen del estado de sitio. De este modo, la Carta Constitucional denota un triunfo sobre el exceso del poder, y el modelo de control constitucional usado por la Corte Constitucional colombiana es un ejemplo que seguir por Estados latinoamericanos, en donde lo excepcional se ha convertido en regla, y los ciudadanos se han acostumbrado a convivir con esta contradicción 9 .

\footnotetext{
${ }^{6}$ Solo en el segundo semestre del 2019 se declararon estados de excepción en Perú, Ecuador, Chile y Bolivia y en el 2020, año de la pandemia del COVID-19, los gobiernos aumentaron sus poderes para enfrentar la amenaza del virus ya sea con la declaración del estado de emergencia en Colombia y Perú, delegación legislativa en argentina, estado de excepción por catástrofe en Chile, entre otros.

${ }^{7}$ En el periodo comprendido de 1991 hasta 2019, ha habido seis declaratorias del estado de conmoción interior: tres de ellas en el gobierno de César Gaviria Trujillo (1990-1994), dos en el gobierno de Ernesto Samper Pizano (1994-1998), y la última en el año 2002, en la primera semana de gobierno de Álvaro Uribe Vélez (2002-2010). Valga resaltar que en los gobiernos de Andrés Pastrana Arango (1998-2002), Juan Manuel Santos Calderón (2010-2018) y en lo que va del de Iván Duque Márquez (2018-2019) no se ha declarado el estado de conmoción interior.

${ }^{8}$ Corte Constitucional. Sentencia C-802 del 2 de octubre de 2002. M. P. Jaime Córdoba Triviño.

9 “El constitucionalismo ha sentado, desde su origen, una demanda para controlar el poder del Estado, a través de la formulación de la regla de derecho, asumida como un conjunto de reglas aplicable a todos los integrantes del juego constitucional" Camargo (2010), p. 31... "pero ¿responde la regla de derecho satisfactoriamente a su promesa implícita de reglar a todos los actores del juego constitucional?" Camargo (2010), p. 32.
} 
Este escrito se ocupa de solo uno de los tres estados de excepción que prevé la Constitución de Colombia y es la conmoción interior (Artículo 213 de la Constitución Política de Colombia, en adelante CP), sin abordar la guerra exterior (Artículo 212 CP) y la emergencia social, económica y ecológica (Artículo 215), pero muchos de los límites y controles establecidos por el constituyente de 1991 son comunes a los tres. Lo anterior es relevante en momentos donde la crisis global generada por la pandemia del COVID-19, sirve de excusa para aumentar los poderes del Ejecutivo y menoscabar derechos fundamentales y sus garantías.

\section{La constitución de 1886: un estado de sitio permanente en Colombia}

“En la actualidad el concepto de la excepción como regla, o simplemente, de la excepcionalidad no solo ha sido utilizado desde orillas teóricas contrapuestas (como las de Schmitt ${ }^{10}$ y Benjamín ${ }^{11}$ ) sino también desde tendencias políticas que en principio defienden ideologías divergentes"12. Así, desde la Primera Guerra Mundial, aunque el estado de excepción no se encuentre formalmente regulado en algunas constituciones de la América Latina, lo cierto es que esta figura ha sido utilizada a lo largo del siglo XX y del siglo XXI en los distintos países como una forma de enfrentar las crisis de distinto orden, bien sean políticas, sociales, económicas o las también llamadas ecológicas o por grave calamidad pública, causadas por los desastres naturales y ahora incluso por una pandemia.

Así, desde la I Guerra Mundial el mundo vive en constantes crisis, que son seguidas por períodos de normalidad. Incluso es posible afirmar que "en algunos países del mundo, el gobierno de crisis se ha trasformado más en la regla que en la excepción"13. En definitiva, se vislumbra que la democracia tendrá que acostumbrarse a convivir con el gobierno de crisis porque hasta la fecha no se han encontrado respuestas dentro de la normalidad para enfrentar las graves perturbaciones que afectan al Estado constitucional de derecho. "La persistencia de las crisis y la ausencia de imaginación han hecho que a una emergencia le siga otra, y a ésta una

\footnotetext{
${ }^{10}$ Schmitt (1999), p. 10

11 Sobre la interesante discusión que habría tenido lugar entre Schmitt y Benjamín acerca del nexo entre violencia y estado de excepción, ver Agamben (2005), pp. 24-28.

12 Tobón (2019), p. 427.

13 Loewenstein (1976), p. 283.
} 
nueva emergencia o el retorno a la anterior, convirtiéndose la normalidad y la estabilidad en utopías"14, “invirtiéndose los conceptos de regla y excepción”15.

No obstante, cabe resaltar que una vez finalizó la Segunda Guerra Mundial16, y fue aprobada la Declaración Universal de Derechos Humanos por la Organización de las Naciones Unidas la dignidad puso cortapisas a los poderes exorbitantes sometiéndolos al principio de proporcionalidad, pero además instaurando acciones destinadas a evitar los abusos de la autoridad y en fin "estableciendo la responsabilidad de esta, por las irregularidades que pudiera cometer en la aplicación de las medidas adoptadas en dichos estados de excepción"17.

De este modo, el uso de los poderes excepcionales ha sido un mecanismo para atropellar al Estado de derecho no solo en Europa, sino en los países latinoamericanos "no solo porque la fuerza destruye el derecho, sino también y sobre todo porque la declaratoria del estado de excepción es una estrategia de guerra controlada, y más que actuar como un instrumento para la paz, contribuye al detrimento de esta"18. En efecto, en la mayor parte de los países donde se ha habituado este mecanismo, en lugar de lograr la paz, su uso generalmente es una excusa para ejercer la dictadura, quebrantando el principio democrático, dada la indebida incorporación de normas al ordenamiento jurídico, que resultan desproporcionadas con respecto a los mandatos constitucionales.

Como se dijo antes, en Colombia el estado de sitio fue usado de manera permanente para dar respuesta al fenómeno de la violencia ejercida por parte de los grupos armados irregulares y el narcotráfico. No obstante, y pesar de las declaratorias de estado de sitio, y de las medidas adoptadas durante el mismo, como eran por ejemplo, el toque de queda y las limitaciones a las libertades individuales, la criminalidad, el terrorismo, la ofensiva de los grupos armados insurgentes siguió produciendo un alto índice de asesinatos selectivos, dando lugar a "una guerra irregular, prolongada de manera indefinida en el tiempo", entendiendo por ella "una confrontación armada permanente que involucra civiles, militares y grupos armados ilegales"19.

\footnotetext{
${ }^{14}$ Rosatti (2004), p. 461.

${ }^{15}$ Justiniano (2010), p. 248.

${ }_{16}$ Para ampliar la noción sobre las narrativas dominantes en el campo de los totalitarismos y la justicia internacional en la se gunda guerra mundial podrá consultarse el libro "La justicia en la mesa de sacrificios de la historia: la culpa de la guerra en Arendt y Jaspers", traducción y ensayo introductorio de Gustavo José Rojas Páez.

${ }^{17}$ Ríos (2009), p. 280.

18 Tobón (2019), p. 428.

${ }^{19}$ Viridiana (2013), p. 255.
} 
La guerra irregular influye indudablemente en el desarrollo constitucional del Estado; lo que no es una situación excepcional si se tiene en cuenta que en Colombia, desde el periodo de independencia y durante todo el siglo XIX, se libraron nueve guerras civiles, mientras paralelamente se expidieron Constituciones para imponer las políticas de quienes resultaron ganadores ${ }^{20}$.

En ese sentido, y tal como afirma Valencia Villa, en Colombia las constituciones han sido cartas de batalla, porque se construyó el Estado antes que la nación, en sus propias palabras el referido autor expresa que

Con base en la idea del derecho como gramática de guerra y en la visión de la independencia como creación del Estado, antes de la nación y sin la nación, de una manera autoritaria y legalista, nuestra revisión histórica muestra cómo las cartas del siglo XIX y las reformas del siglo XX constituyen un interminable conflicto civil, la guerra del país contra sí mismo ${ }^{21}$.

Conforme a lo anterior, "el origen de la República de Colombia se remonta al 30 de agosto de 1821: el Congreso de Cúcuta actuando como cuerpo legislativo y constituyente proclama la Constitución de la Republica de Colombia, la cual fue la primera carta política que rigió durante la Gran Colombia (1819-1830)”22, ratificando la conformación de la nación por tres departamentos: Cundinamarca, Venezuela y Quito, en esta Constitución se conciben los poderes de excepción como un derecho legítimo y constitucional del Estado para su autoconservación. Esta que fue la Constitución de la Gran Colombia, en sus artículos $121^{23}, 55^{24}$ y 12825, otorga

\section{${ }^{20}$ Ibíd.}

${ }^{21}$ Valencia (1987), p. 115.

${ }^{22}$ Echeverri (2014), p.7.

${ }^{23}$ Constitución de Cúcuta de 1821: “Artículo 121: En los casos de guerra exterior o de conmoción interior, podrá el presidente de la República, previa audiencia del Consejo de Estado, y con la firma de todos los Ministros, declarar turbado el orden público, y en Estado de Sitio a toda la República o Parte de ella. Mediante tal declaración quedará el presidente investido de las facultades que le confieran las leyes, y, en su defecto, de las que da el Derecho de Gentes para defender los derechos de la Nación o reprimir el alzamiento. Las medidas extraordinarias o decretos de carácter provisional, legislativo, que dentro de dichos límites dicte el presidente, serán obligatorios siempre que lleven la firma de todos los ministros. El Gobierno declarará restablecido el orden público luego que haya cesado la perturbación o el peligro exterior; y pasará al Congreso una exposición motivada de sus providencias. Serán responsables cualesquiera autoridades por los abusos que hubieren cometido en el ejercicio de facultades extraordinarias".

${ }^{24}$ Constitución de Cúcuta de 1821, Artículo 55: “Son atribuciones exclusivamente propias del Congreso (...) Vigesimoquinta: Conceder al Poder Ejecutivo, durante la presente guerra de la independencia, aquellas facultades extraordinarias que se juzguen indispensables en los lugares que inmediatamente están sirviendo de teatro a las operaciones militares; y en los recién Liber tados del enemigo; pero detallándolas en cuanto sea posible, y circunscribiendo el tiempo que solo será el muy necesario".

${ }^{25}$ Constitución de Cúcuta de 1821, Artículo 128: “En los casos de conmoción interior a mano armada, que amenace la seguridad de la República; y en los de una invasión exterior y repentina, puede, con previo acuerdo y consentimiento del Congreso, dictar todas aquellas medidas extraordinarias que sean indispensables, y que no estén comprendidas en la esfera natural de sus atribucione s. Si el Congreso no estuviese reunido tendrá la misma facultad por sí solo; pero lo convocará sin la menor demora, para proceder conforme a sus acuerdos. Esta extraordinaria autorización será limitada únicamente a los lugares y tiempos indispensablemente necesarios". 
amplias facultades al Ejecutivo y se autoriza expresamente la suspensión de la Constitución cuando el orden se encontraba turbado por el conflicto armado.

La Constitución Política de 1830, así como la de 1843, no reguló este mecanismo, pero ambas sí le otorgaron al presidente de la República la facultad de mantener el orden público ante un eminente ataque exterior. En medio de estas constituciones, en la Constitución de 1832 se da una normatividad más precisa de la conmoción interior, limitando los poderes del Ejecutivo ${ }^{26}$.

Las constituciones de 1853, 1858 y 1863 fueron más liberales, y no consagraron expresamente la figura del estado de excepción, pero sí le otorgaron al presidente facultades para declarar la guerra exterior, con la autorización previa del Congreso.

Más autoritaria fue la Constitución de 1886, que en su artículo 121 le otorgó al Presidente la posibilidad de decretar el estado de sitio, sin establecer un tiempo determinado en el uso de tales facultades. Bajo esta normativa el presidente sustituyó la facultad legislativa del Congreso y vulneró las garantías y las libertades individuales de los ciudadanos.

No obstante, con la finalidad de establecer algunas garantías durante los estados de excepción, el referido artículo 121 fue modificado mediante los siguientes actos legislativos: el Acto legislativo 3 de 1910, el Acto legislativo 1 de 1960 y el Acto legislativo 1 de 1968. Pero a pesar de ellos, los poderes excepcionales se siguieron utilizando casi de una manera permanente 27 . García Villegas sostiene que "desde el cierre del Congreso —en noviembre de 1949, durante el gobierno de Mariano Ospina Pérez (1946-1950) — hasta la expedición de la Constitución de 1991, Colombia vivió prácticamente en un régimen de excepción permanente28.

Asimismo, es importante señalar que, al amparo del estado de sitio, el Gobierno expidió normas que vulneraron gravemente el Estado de derecho y la democracia, porque durante décadas el Poder Legislativo, perdió su principal función "hacer las leyes", y en cambio, el Gobierno incorporó al ordenamiento jurídico de manera permanente, normas que fueron producto de las facultades excepcionales. Sin duda alguna, el Gobierno sustituyó al Congreso, y de esa forma "un régimen que debía ser de excepción y de duración transitoria, en la práctica se

\footnotetext{
${ }^{26}$ Echeverri (2014), pp. 8-10.

${ }^{27}$ Para García Villegas: "en Colombia, la Constitución pocas veces ha regido en forma plena. Una prueba de ello es el recurso permanente que los gobiernos han hecho a los mecanismos de excepción. Así, en la época de la llamada Regeneración (1886-1910), el país fue gobernado durante 24 años con base en una norma 'transitoria' —la disposición $\mathrm{K}$ - y en una ley muy represiva —la Ley 61 de 1888 o Ley de los Caballos-, que autorizaban al Ejecutivo a reprimir administrativamente los abusos de prensa, los delitos contra el orden público, las conspiraciones, etc.".

${ }^{28}$ García y Uprimny (2001), p. 317.
} 
convirtió en un elemento normal y cotidiano de ejercicio del poder político, con lo cual el régimen constitucional se desfiguró" 29.

No obstante, y pesar de las declaratorias de estado de sitio, y de las medidas adoptadas durante el mismo, como eran por ejemplo el toque de queda y las limitaciones a las libertades individuales, la criminalidad, el terrorismo, y el actuar desbordado de los grupos insurgentes se acrecentaba, de este modo, el estado de sitio se tornó en un mecanismo ineficaz porque la violencia en Colombia siguió incrementándose ${ }^{30}$.

Actos atroces ocurrieron en la historia colombiana, cabe recordar, por ejemplo, la toma que realizó el M-19 en la ciudad de Florencia en el año 1984, y un mes y medio más tarde el asesinato del Ministro de Justicia Rodrigo Lara Bonilla a manos del cartel de Medellín. Estos sucesos tan desfavorables para una vida republicana, fueron la causa principal para que el Presidente Belisario Betancur declarara el estado de sitio indefinidamente mediante el Decreto 1038 de 1984, el cual se mantuvo hasta 1990, año en el que gracias a un movimiento estudiantil conocido como "La séptima papeleta" el presidente Virgilio Barco Vargas mediante el uso de los poderes excepcionales e invocando el Decreto 1038 de 1984, que había promulgado Belisario Betancur Cuartas, declaró de nuevo el estado de sitio mediante el Decreto 927 de 1990, convocando a los ciudadanos para que en las elecciones presidenciales del 27 de mayo de 1990 se pronunciasen en una consulta popular sobre la posibilidad de convocar o no a una Asamblea Nacional Constitucional con la finalidad de reformar la Constitución, porque la vieja Constitución de 1886 no daba respuestas efectivas a los cambios sociales, económicos y políticos que había sufrido la sociedad colombiana a lo largo de un siglo ${ }^{31}$.

En ese panorama, y dada la tradición histórica del uso del estado de sitio, uno de los debates más importantes que se llevaron a cabo en el seno de la Asamblea Nacional Constituyente de 1991, fue el que giró en torno a los estados de excepción, y que estuvo caracterizado por el fuerte rechazo al uso de los poderes excepcionales por parte de los delegatarios de la Asamblea Nacional Constituyente de 1991, pues el antiguo régimen consagrado en el artículo 121 de la Constitución de 1886 facilitaba la incorporación normativa de códigos y estatutos, contrariando el principio democrático y la tarea esencial del Congreso de hacer las leyes. Fue tal la influencia

\footnotetext{
${ }^{29}$ García y Uprimmy (2009), p. 3.

30 "Se ha dicho que la democracia colombiana ha sobrevivido gracias a la frecuente utilización del régimen de excepción. Quienes defienden las virtudes de este método de gobierno agregan que en un país en vía de desarrollo se necesita un gobi erno fuerte que pueda dirigir la economía y protegerse de los ataques de los grupos insurgentes”. Cepeda, Op. Cit., p. 21.

31 Para ampliar información sobre el estado de sitio ver Barreto (2011).
} 
que ejerció el estado de sitio en Colombia, que Gustavo Gallón expresa "de la experiencia allí vivida [Colombia] se aprecia claramente que el estado de sitio es una falacia ${ }^{32}$, que su utilización está íntimamente relacionada con la militarización de la sociedad y, en fin, que se trata de una institución profundamente antidemocrática"33.

Como conclusión primigenia, podemos afirmar que durante la vigencia de la Constitución de 1886 el uso de los poderes excepcionales en Colombia fue abusivo y desproporcionado, pues de ninguna manera se tuvieron en cuenta los derechos fundamentales como límite a la actuación arbitraria del Estado durante el uso de las facultades excepcionales, y debido a la ausencia de un control constitucional integral a los decretos legislativos por parte de la Corte Suprema de Justicia, quien solo realizaba un control formal de los decretos legislativos, como se verá más adelante, el Gobierno aprovechándose de esta circunstancia, usó excesivamente competencias extraordinarias, y legisló sobre todas las áreas económicas, sociales y políticas del país, con el pretexto de garantizar la paz y restaurar el orden turbado.

\section{La constitución de 1991: una apuesta por la regulación del estado de conmoción interior}

Como se dijo antes, Colombia estuvo en estado de sitio aproximadamente durante un siglo, en el cual el Poder Ejecutivo utilizó las facultades excepcionales a su capricho y discrecionalidad, sin ningún control que hiciese una barrera infranqueable para proteger los derechos y las libertades fundamentales de los ciudadanos. Por eso, la Asamblea Nacional Constituyente, cuando reguló la figura del estado de conmoción interior en la Constitución de 1991 se inclinó por adoptar un modelo intermedio de las facultades excepcionales, concediéndole al Ejecutivo ciertas facultades que podían ser utilizadas solamente si eran dadas conforme al sistema de límites, controles y garantías previsto por la Constitución de 1991 para limitar el uso abusivo de los poderes excepcionales.

Para García Villegas “esta posición intermedia ha sido recogida en parte por los instrumentos internacionales de derechos humanos"34. En consecuencia, podemos afirmar que la regulación prevista en el ordenamiento jurídico colombiano sobre los estados de excepción en general y el de conmoción interior en particular a partir de la expedición de la Constitución de 1991, se

\footnotetext{
32 Autores como Mauricio García Villegas concluyen que "Entre 1984 y 1991 se dictaron 237 decretos de estado de excepción. Por aquella época el estado de sitio no tenía límites temporales" García y Uprimny (2009), p. 11.

33 Gallón (1987), pp. 80-91.

${ }^{34}$ García y Uprimny (2005), p. 6.
} 
encuentra conforme a los estándares de protección que regulan el derecho internacional de los derechos humanos y el derecho internacional humanitario.

En ese sentido, la Constitución de 1991, dio una vuelta de tuerca al antiguo estado de sitio, regulando el tema de los estados de excepción, con el propósito de limitar el ejercicio abusivo de los mismos por parte del Ejecutivo, consagrando un sistema de controles y garantías que contempla una variedad de requisitos de forma y de fondo, consagrados expresamente en el Titulo VII, capítulo VI, artículos del 212 al 215 del Texto Superior. En estos artículos la Constitución de 1991 estipula tres clases de estados de excepción: el Estado de guerra exterior (art. 212), el Estado de conmoción interior (art. 213) y el Estado de emergencia por motivos de orden económico, social, ecológico o calamidad pública (art. 215).

Sobre la naturaleza del estado de conmoción interior, que así se llama en la Constitución de 1991 el antiguo estado de sitio, y que es el que nos interesa analizar en este ensayo, debemos resaltar que su hecho habilitante es "la grave perturbación del orden público que atente de manera inminente contra la estabilidad institucional, la seguridad del Estado, o la convivencia ciudadana", de conformidad con el nuevo mandato constitucional contemplado en el artículo 213 de la Constitución Política. Del cual también se desprende que, para llevar a cabo la declaración del mismo en todo el país o parte de la República, se requieren las firmas del Presidente y todos sus ministros. Pero lo más importante es resaltar que, a diferencia de la Constitución de 1886, en la que el estado de sitio podía ser declarado de forma indefinida, el nuevo artículo 213 consagró un límite temporal consistente en que la declaratoria del estado de conmoción interior se hará por un término inicial de "90 días prorrogables por dos períodos iguales, siempre y cuando medie concepto previo y favorable del Senado". De este modo, el estado de conmoción interior solo puede ser declarado por 90 días, y podrá ser prorrogado en dos periodos iguales, siempre que exista un concepto previo y favorable por parte del Senado de la República, lo que no ha sucedido en vigencia de la Constitución de 1991.

Asimismo, el artículo 213 prescribe que debe haber un presupuesto fáctico consistente en "la grave perturbación del orden público que no pueda ser conjurada mediante el uso de atribuciones ordinarias de las autoridades de policía", con este presupuesto según Camargo "se limita la discrecionalidad del Ejecutivo quien deberá presentar las pruebas pertinentes ante la Corte Constitucional, con el fin de que esta declare la satisfacción del presupuesto de suficiencia 
que impone la Carta"35. Sin embargo, los conceptos de "estabilidad institucional", "seguridad del Estado" o "convivencia ciudadana" para Tobón y Mendieta "son ambiguos e imprecisos, si se tiene en cuenta que Colombia desde su independencia ha estado en una permanente inestabilidad institucional" 36 .

Por ende, "la interpretación que de esta afectación le dé el Poder Ejecutivo puede ser bastante amplia dejando un considerable margen de discrecionalidad al presidente" 37 . En consecuencia, la discrecionalidad del Gobierno al declarar el estado de excepción está dada por la posibilidad que tiene de decidir políticamente el momento oportuno y necesario para hacer tal declaratoria ${ }^{38}$. Por ello, una vez se ha declarado el estado de conmoción interior, de conformidad al artículo 189-4 de la Constitución Política, al presidente le corresponde "conservar en todo el territorio el orden público y restablecerlo cuando sea turbado". La recuperación del orden no sería posible si no se reconociera al Gobierno un adecuado margen de discreción, que la Corte Constitucional lo ha denominado "discreto".

Cabe señalar que la Ley 137 de 199439, en adelante LEEE, le otorga al Presidente de la República entre otras, las siguientes facultades durante los estados de excepción:

Las facultades del Presidente para restringir el derecho de circulación y residencia (art. 24 C. P.), así como el derecho de reunión y las manifestaciones públicas (art. 37 C. P.); el uso de servicios y consumo de artículos (art. 78 C. P.); a la libertad de expresión de los medios de comunicación (art. 20 C. P.); para imponer el toque de queda (art. 24 C. P.); para suspender servicios de radiocomunicación (art. 20 C. P.); suspender y reemplazar temporalmente alcaldes y gobernadores (arts. 304 y 314 C. P); imponer contribuciones fiscales y parafiscales (art. 215 C. P.) ${ }^{40}$.

Además, es necesario precisar que "las facultades del Presidente no pueden rebasar el núcleo esencial del derecho fundamental que se limita", lo cual se encuentra prescrito en el artículo 7 de la Ley 137 de 1994 en los siguientes términos:

Artículo 7. Vigencia del Estado de derecho: “En ningún caso se podrá afectar el núcleo esencial de los derechos fundamentales. El Estado de Excepción es un régimen de legalidad y por lo tanto no se podrán cometer arbitrariedades so pretexto de su declaración. Cuando un derecho o una libertad fundamentales puedan ser restringidos o su ejercicio reglamentado mediante decretos

\footnotetext{
${ }^{35}$ Camargo (1996), p. 79.

36 Tobón y Mendieta (2017), p. 78.

${ }^{37}$ Camargo (1996), p. 79.

38 Para ampliar el tema de la discrecionalidad del presidente consultar la siguiente jurisprudencia de la Corte Constitucional de Colombia: Sentencias C-004 de 1992, C-300 de 1994, C-466 de 1995, C-027 de 1996, C-802 de 2002, C-070 de 2009.

${ }^{39}$ Ley 137 de 1994 (junio 2) por la cual se regulan los estados de excepción en Colombia. Diario Oficial. № 41379. Junio 3 de 1994.

40 Tobón (2019), p. 115.
} 
legislativos de Estados de Excepción, estos no podrán afectar el núcleo esencial de tales derechos y libertades" 41 .

En ese sentido, es necesario resaltar que uno de los límites constitucionales más importantes que tiene el Gobierno durante los estados de excepción en Colombia, es la prohibición de la suspensión de los derechos humanos y las libertades fundamentales, el cual se encuentra consagrado expresamente en el artículo 214-2 de la Constitución de 1991 así: durante los estados de excepción "no podrán suspenderse los derechos humanos ni las libertades fundamentales". Esta prohibición también se encuentra consagrada en el artículo 5 de la LEEE42. Sobre la imposibilidad de suspensión de los derechos y las libertades públicas Tobón Tobón afirma que:

En Colombia, a diferencia de otros países y de la naturaleza misma de la figura del estado de excepción, el artículo 214.2 de la Constitución de 1991 integra un plus al ordenamiento jurídico colombiano, este plus va más allá de las normas del derecho internacional comparado, al prohibir expresamente la suspensión de los derechos humanos y las libertades fundamentales durante los estados de excepción, aunque no se trate de derechos intangibles, ni hagan parte del núcleo duro de los derechos humanos, los cuales no pueden ser suspendidos durante épocas de crisis o estados de excepción, de conformidad con el artículo 27 de la CADH y el artículo 4 del PIDCP y Políticos, quienes consagran expresamente el núcleo duro de derechos humanos ${ }^{43}$.

En resumen, además de la prohibición de la suspensión de los derechos fundamentales, otro de los límites esenciales es la imposibilidad de restringir el núcleo esencial de los derechos humanos. Solamente es posible realizar una restricción si ella no conlleva la suspensión en el uso y goce del derecho. Pero determinar el contenido esencial de cada derecho es una tarea que le corresponde fijar a los jueces y al Tribunal Constitucional, como intérprete supremo de la Constitución. En todo caso, toda restricción a un derecho es excepcional y por lo tanto deberá justificarse sin dejar ninguna duda, teniendo en cuenta los principios que rigen durante los estados de excepción, como son los de proporcionalidad, finalidad, intangibilidad, y el de necesidad entre las medidas que se adopten y las causas que dieron lugar a la declaratoria del estado de excepción etc.

Sobre el control de los estados de excepción, la Corte Constitucional ha reiterado que en virtud del mandato constitucional señalado en los artículos 241-7 y 214-6 de la Constitución Política "debe ser un control estricto y riguroso para evitar la eventual vulneración de los preceptos superiores a los que deben sujetarse tanto su declaratoria, como los decretos de

\footnotetext{
${ }^{41}$ Ley 137 de 1994, artículo 7.

42 Para ampliar el tema de la suspensión de derechos en estados de excepción ver el libro basado en la tesis doctoral de la auto ra de este ensayo titulado: "Los estados de excepción: Imposibilidad de suspensión de los derechos humanos y las libertades fundamentales" Tobón (2019).

43 Tobón (2011), p. 65.
} 
desarrollo de las facultades de las que se inviste temporalmente al Ejecutivo" ${ }^{44}$. Por eso, el constituyente de 1991 estableció tres tipos de controles que recaen sobre los decretos legislativos emanados de los estados de excepción, ellos son: un control jurídico, realizado por la Corte Constitucional ${ }^{45}$, otro de carácter político, ejecutado por el Congreso de la República ${ }^{46}$, y un tercer control de legalidad sobre los decretos que contienen las medidas expedidas por el Gobernador o por el Alcalde para dar respuesta a la crisis, ejercido por el Tribunal Contencioso Administrativo.

En ese sentido, el control constitucional de Colombia sobre los estados de excepción es un ejemplo de la tesis de la supremacía judicial, pues la Corte Constitucional tiene la competencia final para decidir la constitucionalidad o no del ejercicio de las facultades excepcionales.

Los presupuestos teóricos sobre los que descansa esta prerrogativa son dos. El primero es una determinada concepción de la supremacía constitucional, que implica su garantía jurisdiccional. El segundo es la naturaleza del acto que declara un estado de excepción constitucional, que se estima eminentemente jurídico y no político ${ }^{47}$.

Cabe aclarar que las normas expedidas por el Ejecutivo durante los estados de excepción en Colombia, a diferencia de otros países, se denominan decretos legislativos. Estos decretos "revisten un carácter transitorio y excepcional, ya que su vigencia se encuentra limitada al período de alteración del orden público, derogándose tan pronto como éste se declare reestablecido"48. Aunque se encuentran condicionadas al control político del Congreso, hasta ahora no ha ejercido de manera efectiva esta competencia, las normas son sometidas a un control automático y posterior por parte de la Corte Constitucional, pues esa obligación que deriva del artículo 241.7 de la Constitución de 1991, al tenor del cual: "le corresponde a la Corte decidir definitivamente sobre la constitucionalidad de los decretos legislativos que dicte el Gobierno con fundamento en los artículos 212, 213 y 215 de la Constitución”. A tal efecto, "el Gobierno debe

\footnotetext{
${ }^{44}$ Corte Constitucional. Sentencia C-216 del 29 de marzo de 2011. Magistrado Ponente. Juan Carlos Henao Pérez.

${ }_{45}$ Con respecto al control jurídico la Corte Constitucional ha dicho: "En síntesis, de la Carta Política se infiere la competencia de la Corte Constitucional para realizar el control de constitucionalidad formal y material tanto de los decretos legislativos declaratorios de los estados de excepción como de los decretos legislativos de desarrollo. Tal competencia es corroborada además por las deliberaciones a que hubo lugar en la Asamblea Nacional Constituyente; por el modelo del derecho constitucional de excepción por el que optó el Constituyente de 1991; por la regulación que aquél hizo de la naturaleza, límites y sistema de control del estado de conmoción interior; por la naturaleza jurídica del decreto declaratorio de tal estado de excepción y por la concep ción actual de la jurisdicción constitucional y de su función". Corte Constitucional. Sentencia C-802 de 2002, Op. Cit.

${ }^{46}$ Sobre el control político, la Corte Constitucional ha dicho que: "como corresponde a un sistema constitucional democrático, en el cual estén contemplados instrumentos de control entre órganos para evitar la concentración de poder y las posibilidades de abuso del gobernante, resulta apenas natural que el cuerpo representativo de elección popular sea el que por derecho propio, y también como una función que justifica su existencia, fiscalice, desde las perspectivas de la conveniencia, la oportunidad, la viabilidad política y el interés público, la actividad del Jefe del Estado cuando, por su propia determinación, asume un mayor cúmulo de facultades que pueden implicar restricciones a los derechos y libertades públicas y que de suyo -en los estados de excepciónrepresentan un desplazamiento de las atribuciones del Congreso hacia el Ejecutivo". Corte Constitucional. Sentencia C-565 del 6 de noviembre 1996. Magistrado Ponente. José Gregorio Hernández Galindo.

${ }^{47}$ Silva (2018), p. 88.

${ }^{48}$ Reguera (2005), p. 106.
} 
enviarlos a la Corte Constitucional al día siguiente de su expedición”, con el fin de que decida si se ajustan a la Constitución. "Si el Gobierno no cumpliere con el deber de enviarlos, la Corte Constitucional aprehenderá de oficio y en forma inmediata su conocimiento" (art. 214.6 C. P.), configurándose un control de constitucionalidad posterior, automático e integral ${ }^{49}$.

Se trata, por ello, de una revisión automática, e integral, en la medida que el control ejercido lo es tanto por vicios de forma como por vicios materiales o de contenido, utilizando como parámetro al respecto la totalidad de los preceptos constitucionales y las disposiciones de la LEEE. Por tanto, la Corte no solo realiza un control de constitucionalidad meramente formal de los decretos, limitado a confirmar la existencia de una motivación formal del estado de excepción, la firma del Presidente y los Ministros y la restricción temporal, sino también material, para verificar que las medidas adoptadas no supongan una violación de las normas constitucionales, con particular cuidado de la parte relativa a los derechos fundamentales, ya que los estados de excepción no pueden significar su alteración por decreto ${ }^{50}$.

Sobre el control material es necesario señalar que la Corte Constitucional también verifica que "las materias reguladas en el decreto legislativo tengan relación directa y específica con la situación que hubiere determinado la declaración del estado de excepción" 51 , si no hay conexidad entre las medidas y las causas, la Corte deberá declarar la inconstitucionalidad del referido decreto. Sobre el control integral de los decretos declaratorios y de los decretos de desarrollo en la Sentencia 802 de 2002 la Corte dijo que:

En suma, el condicionamiento material que la Carta de 1991 hace del estado de conmoción interior no solo determina la legitimidad o ilegitimidad constitucional del decreto legislativo declaratorio, sino que también constituye el ámbito de sujeción de los decretos legislativos de desarrollo dictados con base en él. En consecuencia, si el acto declaratorio no satisface ese condicionamiento, contraría la Carta y deberá ser retirado del ordenamiento. Y si los decretos de desarrollo dictados con base en él no están directa y específicamente relacionados con los motivos de la declaración, contrarían también el ordenamiento constitucional y deberán ser declarados inexequibles ${ }^{52}$.

\footnotetext{
${ }^{49}$ Mendieta (2018), p. 60.

${ }^{50}$ Reguera (2005), p. 106.

${ }^{51}$ Ibid.

52 Corte Constitucional de Colombia, Sentencia C-802 de 2002.
} 
Se termina este acápite concluyendo que, bajo el régimen actual de los estados de excepción en Colombia, se ha avanzado mucho, sobre todo con respecto al control jurídico que es el realizado por la Corte Constitucional, el cual, a partir de la Constitución de 1991, es un control integral, y no solo formal como ocurría con el control realizado por parte de la Corte Suprema de Justicia, a la luz de la Constitución de $1886^{53}$. En el régimen de los estados de excepción en Colombia, la Corte Constitucional colombiana no solo revisa la forma sino el contenido material de la declaratoria del estado de excepción, para el caso que nos ocupa del estado de conmoción interior, esto es, los decretos legislativos deberán ser expedidos conforme al conjunto de valores, principios y derechos constitucionales consagrados en la Constitución de 1991 y demás normas que hacen parte del bloque de constitucionalidad de Colombia. No obstante, cabe resaltar que no se realizó un análisis del control político que debería efectuarse a los decretos legislativos por parte del Congreso, debido a la ausencia de este. Así mismo, el control de los órganos internacionales a las medidas excepcionales es inexistente, a pesar de la obligación que tienen los gobiernos de enviar copia de la declaratoria del estado de excepción y de las medidas adoptadas a la Secretaría General de las Naciones Unidas (art. 4, numeral 3 del PIDCP, y art. 27 $\mathrm{CADH})$.

\section{El control constitucional del estado de conmoción interior: un ejemplo a seguir en el derecho comparado}

Después de 105 años de vigencia de una Constitución autoritaria, la Constitución de 1991 se perfiló como una Constitución para la paz, porque con ella se intentaba superar la guerra irregular que durante más de sesenta años mantuvo a la población sumida en la crisis y la anormalidad. Por eso, en el capítulo VI denominado Sobre los estados de excepción, de la Constitución Política y la Ley Estatutaria 137 de 199454, encontramos una regulación extensa de los estados de excepción, con un sistema amplio de controles, límites y garantías para proteger los derechos de los ciudadanos. Pero en este artículo nos interesa el uso que se ha hecho de esta figura desde 1991 hasta 2019, resaltando los decretos legislativos que han vulnerado los

${ }^{54}$ Ley 137 de 1994, Op. Cit. 
derechos humanos, y el control constitucional que realizó la Corte Constitucional sobre estas normas, lo que nos permitirá vislumbrar el impacto del control judicial sobre las declaratorias de la conmoción interior durante la Constitución de 1991.

En efecto, podemos afirmar, tal como lo muestra la tabla, que desde que se promulgó la Constitución de 1991 hasta 2019, en total ha habido siete declaratorias de conmoción interior, tres en el gobierno de César Gaviria Trujillo (1990-1994), dos en el gobierno de Ernesto Samper Pizano (1994-1998), y dos durante el gobierno de Álvaro Uribe Vélez (2002-2010). Pero valga resaltar que durante los gobiernos de Andrés Pastrana Arango (1998-2002) y Juan Manuel Santos Calderón (2010-2018) no se declaró el estado de conmoción interior, y cinco de estas declaratorias se realizaron durante los primeros años de haberse promulgado la Constitución de 1991, dado el lastre que había dejado el antiguo régimen del estado de sitio. Además, es importante señalar que solamente dos de ellas fueron respaldadas por la Corte Constitucional en su totalidad, pues otras dos, fueron declaradas parcialmente inexequibles y, las otras tres, fueron declaradas inconstitucionales porque no respondían a una situación de anormalidad institucional verdadera.

Por lo anterior, es posible concluir que en estos veintinueve años de vigencia de la Constitución Política de 1991, la utilización de las facultades excepcionales en Colombia propias del estado de conmoción interior se ve marcado por cuatro momentos importantes: el primer momento (1991-1998) se dio durante los primeros años de entrada en vigencia de la Constitución de 1991, en este se advierte la necesidad del Gobierno de acudir frecuentemente al uso de los poderes excepcionales, dada la funesta tradición histórica que se había heredado del antiguo régimen del estado de sitio. Por ello, el segundo momento solamente aparece a finales del siglo XX, y estuvo caracterizado por el cálculo político que se dio en el gobierno de Andrés Pastrana Arango (1998-2002) quien durante gran parte de su mandato realizó unos diálogos infructuosos con las FARC -EP y no decretó la conmoción interior. Un tercer momento, coincide con la llegada a la presidencia de Álvaro Uribe Vélez (2002-2010), quien desde que llegó al poder declaró la conmoción interior y aunque la Corte Constitucional dijo que era constitucional, fijó un exigente test de constitucionalidad para declaraciones futuras, lo que sucedió en el año 2008, pues en este año el presidente Uribe declaró por segunda vez la conmoción interior, pero fue declarada inexequible, por no cumplir con la exigencias del test antes mencionado y finalmente un cuarto momento, durante los gobiernos de Juan Manuel Santos (2010-2018) e Iván Duque (2018-2020), el primero no declaró la conmoción interior y el segundo a octubre de 2020 
tampoco lo ha hecho, a pesar de haber sucedido algunos hechos que afectan el orden público, lo importante es señalar que ambos gobiernos han evitado acudir al uso de los poderes excepcionales, pues en Colombia es muy difícil que una declaratoria de conmoción interior resista el exigente control de constitucionalidad propuesto por la Corte Constitucional y hasta ahora, ambos mandatarios solucionaron las crisis del orden público con los mecanismos de la normalidad.

A continuación, se narran algunos detalles acerca del uso de la conmoción interior por parte de los presidentes de Colombia desde 1991, así: el Presidente César Gaviria continuó con el antiguo hábito de declarar el estado de sitio, declarando el estado de conmoción interior tres veces en tres años, con los siguientes decretos legislativos: Decreto legislativo 1155 de 1992, Decreto legislativo 1793 de 1992, y Decreto legislativo 0874 de 1994.

La primera declaratoria del estado de conmoción interior en el marco de la Constitución de 1991 fue realizada el 10 de julio de 1992 por el presidente César Gaviria mediante el Decreto legislativo 1155/199255, con el objeto de impedir que las personas que habían sido detenidas por la justicia regional por haber cometido algún delito relacionado con el terrorismo, el secuestro o el narcotráfico, pudiesen ser liberados al hacer uso del habeas corpus, pues conforme al Código de Procedimiento Penal, las personas que estuviesen capturadas más de 180 días en prisión sin que hubieran sido llamados a juicio por parte de la justicia regional tendrían derecho a la libertad provisional. En la Sentencia C-556 de 1992 la Corte declaró exequible el Decreto 1155 de 1992 a pesar de que esta declaratoria negaba el habeas corpus, vulnerando el mencionado artículo 214-2 de la Constitución Política de 1991, que prohíbe suspender los derechos fundamentales durante los estados de excepción. Fueron estas las palabras de la Corte Constitucional "en ningún caso, el habeas corpus fue concebido para perturbar el funcionamiento de la administración de justicia, colocando en tela de juicio las providencias de los mismos jueces en desarrollo de sus facultades legales y constitucionales" ${ }^{56}$.

La segunda declaratoria se realizó mediante Decreto legislativo 1793 de 1992, debido al incremento de las acciones terroristas emprendidas por las organizaciones guerrilleras y, en general, el incremento de la violencia. Una vez más, en la Sentencia C-231 de $1993^{57}$ la Corte

\footnotetext{
55 El Decreto legislativo 1155 de 1992 fue desarrollado por el Decreto 1156 de 1992, el cual en su artículo $3^{\circ}$ prescribe: "En los delitos de competencia de los jueces regionales y del tribunal nacional no procederá la acción de Habeas Corpus, por causales previstas para obtener la libertad provisional, las cuales deben alegarse dentro del proceso respectivo. Tampoco procederá para efecto de revisar la legalidad de las providencias que hubieren decidido sobre la privación de la libertad".

${ }^{56}$ Corte Constitucional de Colombia, Sentencia C-556 de 1992.

${ }^{57}$ Corte Constitucional de Colombia, Sentencia C-231 de 1993.
} 
Constitucional declaró exequible esta norma, olvidando que el enfrentamiento de los grupos armados irregulares en Colombia se registraba desde hacía más de treinta años, por lo que no podría ser un hecho nuevo que legitimara la declaratoria del estado de excepción, sino un hecho que suponía un problema estructural o diacrónico de la sociedad colombiana.

En este panorama, se observa que, en las dos primeras declaratorias del estado de conmoción interior realizadas en el marco de la Constitución de 1991, se suspendieron los derechos fundamentales de los prisioneros como el debido proceso, y el habeas corpus, y a pesar de la inconstitucionalidad de estas normas, ambos decretos fueron declarados exequibles por parte de la Corte Constitucional. Por ello, y tal como afirma Uprimny "esos primeros pasos de la Corte Constitucional -muy osada teóricamente, pero más tímida y vacilante en la decisión concretaterminaron provocando un consenso ambiguo, con respecto al cambio jurisprudencial radical que debía llevar la Corte”58, incluso varios de los constitucionalistas más reconocidos de la época, consideraron que la intervención judicial en estas áreas podía ser ambivalente, porque si bien por un lado podía ser instrumento de control efectivo, por el otro podría ser un mecanismo para legitimar los poderes excepcionales usados por los presidentes de turno.

En los años siguientes, la Corte Constitucional pudo superar la tensión que había para realizar el control integral de los decretos legislativos, ejerciendo un control material mucho más estricto y riguroso sobre estas normas, tal como se demuestra con la declaratoria de inexequibilidad de los decretos legislativos que fueron proferidos presidentes Gaviria y Samper.

En ese sentido, la tercera declaratoria de conmoción interior, realizada por el mismo Gobierno de Gaviria, el 1 de mayo de 1994, mediante Decreto legislativo 874 de 1994, con una finalidad parecida a la segunda declaratoria, pues lo que buscaba también era impedir la salida masiva de los detenidos más peligrosos que llevaban varios meses en la cárcel sin que su situación jurídica fuere resuelta. Valga resaltar que esta norma no tuvo la suerte de las dos declaratorias anteriores, y fue declarada inexequible mediante Sentencia C-300 de 199459. Fue la primera vez en que la Corte Constitucional declaró inconstitucional un decreto legislativo desde que se expidió la Constitución de 1991, en ella la Corte señaló que dos años después de haberse decretado la primera declaratoria, el Gobierno no podía invocar una nueva declaratoria aduciendo las mismas causas del Decreto legislativo 1793 de 1992, pues era evidente que en

\footnotetext{
${ }^{58}$ García y Uprimny, Op. Cit., (2009), p. 13.

${ }^{59}$ Corte Constitucional de Colombia, Sentencia C-300 de 1994.
} 
esos dos años las autoridades estatales no habían adoptado ninguna medida de carácter ordinario para conjurar esa crisis ${ }^{60}$.

La cuarta declaratoria del estado de excepción fue realizada el 16 de agosto de 1995, por el Gobierno de Ernesto Samper, mediante Decreto legislativo 1370 de 1995, con la finalidad de llevar a cabo el fortalecimiento de la justicia y del sistema penitenciario, incorporando al sistema penal nuevos delitos y procedimientos para llevar a cabo la lucha contra la guerrilla y la delincuencia común. Pero esta norma fue declarada inconstitucional mediante la Sentencia C466 de 1995, al considerar que el Ejecutivo no había motivado suficientemente la declaratoria, y la turbación del orden público podía ser enfrentada con los mecanismos normales de defensa del orden institucional ${ }^{61}$.

Sin embargo, un par de meses más tarde, tras el magnicidio del excandidato presidencial Álvaro Gómez Hurtado, el 2 de noviembre de 1995 el gobierno de Samper declaró un nuevo estado de conmoción interior, mediante el Decreto 1900 de 1995 argumentando razones parecidas a la declaratoria anterior. Esta sería la quinta declaratoria del estado de conmoción en menos de cinco años. Esta vez la Corte Constitucional dijo que la declaratoria era en parte constitucional y en parte inexequible ${ }^{62}$. En efecto, en la Sentencia C-027 de 1996, la Corte manifestó que los motivos del Decreto 1370 de 1995, y reproducidos otra vez por el Gobierno en esta norma, no eran viables para decretar un estado de excepción, declarando la inexequibilidad en ese aspecto. Sin embargo, la Corte expresó que el magnicidio del excandidato presidencial Álvaro Gómez Hurtado, y las amenazas a otros líderes, eran hechos nuevos y graves, que justificaban la declaratoria de conmoción 63.

En resumidas cuentas, podemos concluir que si bien en un primer momento, la Constitución de 1991 quería poner límites al uso desproporcionado de los poderes excepcionales, el estado de conmoción interior siguió siendo un mecanismo usado frecuentemente por los distintos presidentes. El Gobierno de César Gaviria lo decretó en tres ocasiones, y el Gobierno de Ernesto Samper en dos oportunidades. En este periodo, la Corte Constitucional fue muy osada teóricamente, pero no realizó un control constitucional integral y efectivo del estado de conmoción interior. Valga resaltar que en este periodo la Corte fue muy atacada, pues el

\footnotetext{
${ }^{60}$ Ibíd.

${ }^{61}$ Corte Constitucional de Colombia, Sentencia C-466 de 1995.

${ }^{62}$ Corte Constitucional de Colombia, Sentencia C-027 de 1996

${ }^{63}$ En esa época la Corte enfrentaba un dilema: "si anulaba esta nueva declaración de conmoción interior, era muy probable que se adelantara una reforma constitu cional para suprimir el control material ejercido por ella” García y Uprimny (2009), p. 14.
} 
Gobierno Samper quería adelantar una reforma constitucional para modificar la competencia que tenía la Corte Constitucional para llevar a cabo el control constitucional sobre las normas expedidas durante los estados de excepción, al respecto Mauricio García opina que:

Sin embargo, la Corte fue igualmente atacada de manera muy fuerte por funcionarios gubernamentales, los gremios económicos, los líderes de los partidos tradicionales y algunos académicos, para quienes esta intervención judicial era una forma de gobierno de los jueces, que no solo invadía competencias propias del presidente, sino que, además, hacía imposible que el Ejecutivo contara con los instrumentos necesarios para restablecer el orden público ${ }^{64}$.

A pesar de lo anterior, tal como lo muestra la tabla, la mayor rigurosidad que de manera gradual fue ejercida por la Corte Constitucional a la hora de realizar el control material e integral, sobre las declaratorias de conmoción interior, parecen haber tenido un efecto considerable para el gobierno siguiente, pues a pesar de la gravedad de la situación de orden público, el gobierno de Andrés Pastrana no hizo uso de esta figura, apareciendo un segundo momento del ejecutivo colombiano con respecto al uso (en este caso no uso) de los poderes excepcionales, caracterizado por el cálculo político de este gobierno, que buscó solucionar los problemas de orden público, mediante el uso de los mecanismos ordinarios, bien a través de políticas legislativas presentadas al Congreso, o por medio del ejercicio de las atribuciones ordinarias que tiene el Presidente de la República, para cumplir con la misión constitucional de conservar el orden público, la seguridad y la convivencia pacífica.

Como se dijo antes, durante el Gobierno de Andrés Pastrana Arango (1998-2002) el estado de conmoción interior no fue declarado por dos motivos: el primero, por "cálculo político", pues su Gobierno estaba en un proceso de negociación con la guerrilla de las FARC -EP y acercamientos con el ELN; el segundo motivo, porque Pastrana pensaba que el uso de la conmoción interior "no servía para nada", pues ni la Constitución ni la Corte le otorgaban al Gobierno las herramientas necesarias que debía tener el presidente una vez se declaraba el estado de excepción.

En efecto, y a pesar de varios atentados guerrilleros en distintas zonas del país, el presidente Pastrana cree en los diálogos de paz. Por ello el 7 de noviembre de 1998 el Gobierno reconoce un estatus político a las FARC, autorizando el despeje por parte de las fuerzas armadas, de la denominada “Zona de distención”, la cual estaba comprendida por 42.130 kilómetros cuadrados

${ }^{64}$ Ibíd. 
en los municipios de La Macarena, Mesetas, Uribe, y Vista Hermosa en el departamento del Meta, y San Vicente del Caguán en el departamento del Caquetá65.

No obstante, a principios del siglo XXI, y una vez fue elegido Álvaro Uribe Vélez, en la primera semana de su gobierno declaró la conmoción interior por medio del Decreto 1837 de 2002, con el fin de dar respuesta a la crisis que había en todo el país por el actuar de los grupos armados irregulares, lo cual solo demuestra la debilidad que tenía el Estado para enfrentar a los grupos terroristas con el uso ordinario de las facultades policivas 66 . Por ello, y a pesar de que este decreto fue declarado exequible en la Sentencia C-802 de $2002^{67}$, es claro que fue en este fallo, donde la Corte Constitucional estableció las reglas del control de constitucionalidad de los decretos legislativos, creando la necesidad de utilizar un juicio de constitucionalidad fundamentado en el uso del principio de proporcionalidad en estricto sentido, impidiendo que el uso de los poderes excepcionales, siguieran siendo usados de manera desproporcional por parte del Presidente de la República.

De hecho, en el año 2008, el gobierno Uribe Vélez intentó declarar por segunda vez el estado de conmoción interior, mediante el Decreto 3929 de 2008, invocando como causal el cese de actividades realizado por los funcionarios de la rama judicial durante más de 40 días, pero la Corte Constitucional, mediante la Sentencia C-070 de 200968, lo declaró inexequible por no cumplir con los presupuestos que son exigidos en el juicio de constitucionalidad.

Como se dijo antes, en gobiernos posteriores como los dos de Juan Manuel Santos y lo que va del gobierno de Iván Duque, no se ha decretado el estado de conmoción interior y Colombia ha pasado por momentos difíciles de orden público, pero ambos mandatarios han decidido acudir a competencias propias de la normalidad y no se han dejado tentar por el uso de los poderes excepcionales, porque han tenido claro el exigente control de constitucionalidad que realiza la Corte Constitucional, a partir del test de proporcionalidad en sentido estricto.

Así, una de las más graves preocupaciones que vivió el Constituyente de 1991, y que giró en torno a la necesidad de colocarle un coto a los poderes desmedidos del estado de sitio, hoy es una promesa cumplida, porque a la luz de la Constitución de 1991, el estado de conmoción

\footnotetext{
65 Tobón (2019), p. 379.

${ }^{66}$ Mediante Decreto 2002 de 2002 el presidente Uribe crea las zonas de rehabilitación, las cuales fueron consideradas como la columna vertebral de la política gubernamental de la Seguridad Democrática, al imponer controles militares de seguridad en las zonas que tradicionalmente eran afectadas por la violencia.

${ }^{67}$ Corte Constitucional de Colombia, Sentencia C-802 de 2002.

${ }^{68}$ Corte Constitucional de Colombia, Sentencia C-070 de 2009.
} 
interior ha caído en desuso, tornándose en un mecanismo ineficaz, prueba de ello es que la última vez que fue declarada la conmoción interior en Colombia con sentencia de constitucionalidad, fue en el año 2002 durante el Gobierno de Álvaro Uribe Vélez. Se resalta que, durante el gobierno de Juan Manuel Santos Calderón (2010-2018), no fue declarado el estado de conmoción interior, y hasta el momento el presidente Iván Duque (2018-2020) tampoco lo ha declarado.

Por lo anterior, y tal como se evidencia en la siguiente tabla se puede concluir que, desde que fue promulgada la Constitución Política de Colombia en 1991, el Gobierno ha declarado el estado de conmoción interior durante 827 días; es decir, que de los 29 años de vigencia de la Constitución Política de 1991, cerca de 2,26 años hemos en estado de conmoción interior, lo cual es un gran avance si se compara con el estado de sitio permanente que hubo en Colombia durante la vigencia de la Constitución de 1886. 
Tabla. Uso de los estados de conmoción interior en Colombia 1991-2019

\begin{tabular}{|c|c|c|c|c|c|c|c|}
\hline GOBIERNO & $\begin{array}{l}\text { DECRETO } \\
\text { LEGISLATIVO } \\
\text { (DL.) }\end{array}$ & $\begin{array}{c}\text { DECRETOS } \\
\text { REGLAMENTARIOS }\end{array}$ & CAUSAS & $\begin{array}{c}\text { CONTROL DE } \\
\text { CONSTITUCIONALIDAD }\end{array}$ & $\begin{array}{l}\text { MEDIDAS } \\
\text { ADOPTADAS }\end{array}$ & $\begin{array}{c}\text { DERECHOS } \\
\text { FUNDAMENTALES } \\
\text { VULNERADOS }\end{array}$ & DURACIÓN \\
\hline \multirow[t]{3}{*}{$\begin{array}{l}\text { César Gaviria } \\
\text { Trujillo } \\
(1990-1994)\end{array}$} & $\begin{array}{l}\text { Primera } \\
\text { declaratoria } \\
\text { Decreto } \\
1155 / 1992\end{array}$ & $\begin{array}{l}\text { Decretos 1156/1992, } \\
\text { 1195/1992, }\end{array}$ & $\begin{array}{l}\text { Eventual } \\
\text { excarcelació } \\
\mathrm{n} \text { masiva de } \\
\text { detenidos } \\
\text { por la justicia } \\
\text { regional }\end{array}$ & $\begin{array}{l}\text { Sentencia C-556 de } 1992 \\
\text { Constitucional }\end{array}$ & $\begin{array}{l}\text { Suspensión del } \\
\text { habeas corpus }\end{array}$ & $\begin{array}{l}\text { Habeas corpus, } \\
\text { libertad personal, } \\
\text { debido proceso }\end{array}$ & 7 días \\
\hline & $\begin{array}{l}\text { Segunda } \\
\text { declaratoria } \\
\text { Decreto } \\
1793 / 1992 \\
1^{\circ} \text { Prórroga } \\
\text { Dcto. } \\
261 / 1993 \\
2^{\circ} \text { Prórroga } \\
\text { Decreto } \\
829 / 1993\end{array}$ & $\begin{array}{l}\text { Decretos 1941/1992, } \\
\text { 1810/1992, } \\
1811 / 1992 \\
1812 / 1992 \\
1834 / 1992\end{array}$ & $\begin{array}{l}\text { Agravación } \\
\text { del orden } \\
\text { público por } \\
\text { acciones } \\
\text { terroristas } \\
\text { de la } \\
\text { guerrilla e } \\
\text { incremento } \\
\text { de la } \\
\text { violencia } \\
\text { general }\end{array}$ & $\begin{array}{l}\text { Sent. C-031/1993, } \\
\text { Sent. C-154/1993, } \\
\text { Sent. C-294/1993 } \\
\text { Constitucional }\end{array}$ & $\begin{array}{l}\text { Se otorgan } \\
\text { funciones de } \\
\text { policía judicial } \\
\text { a las fuerzas } \\
\text { militares. }\end{array}$ & $\begin{array}{l}\text { Debido proceso y } \\
\text { garantías judiciales }\end{array}$ & $\begin{array}{l}90 \text { días } \\
90 \text { días } \\
90 \text { días }\end{array}$ \\
\hline & $\begin{array}{l}\text { Tercera } \\
\text { declaratoria } \\
\text { Decreto } \\
874 / 1994\end{array}$ & & $\begin{array}{l}\text { Ataques } \\
\text { guerrilleros y } \\
\text { amenazas, e } \\
\text { incremento } \\
\text { general de la } \\
\text { violencia }\end{array}$ & $\begin{array}{l}\text { Sentencia C-300/1994 } \\
\text { Inconstitucional }\end{array}$ & & & 10 días \\
\hline \multirow[t]{2}{*}{$\begin{array}{l}\text { Ernesto } \\
\text { Samper } \\
\text { Pizano } \\
(1994-1998)\end{array}$} & $\begin{array}{l}\text { Cuarta } \\
\text { declaratoria } \\
\text { Decreto } \\
1370 / 1995\end{array}$ & $\begin{array}{l}\text { Decretos 1371/1995, } \\
\text { 1372/1995, } \\
1410 / 1995,1531 / 199 \\
5,1532 / 1995, \\
1590 / 1995, \\
1723 / 1995,1724 / 199 \\
5 .\end{array}$ & $\begin{array}{l}\text { Incremento } \\
\text { de la } \\
\text { violencia, la } \\
\text { criminalidad } \\
\text { y los ataques } \\
\text { guerrilleros }\end{array}$ & $\begin{array}{l}\text { Sentencia C-466/1995 } \\
\text { Inconstitucional }\end{array}$ & & & 90 días \\
\hline & $\begin{array}{l}\text { Quinta } \\
\text { declaratoria } \\
\text { Decreto } \\
1900 / 1995 \\
1^{\circ} \text { Prórroga } \\
\text { Dcto. } \\
208 / 1996 \\
2^{\circ} \text { Prórroga } \\
\text { Dcto. } \\
777 / 1996\end{array}$ & $\begin{array}{l}\text { Decretos 1901/1995; } \\
\text { 1902/1995; } \\
\text { 2027/1995; } \\
\text { 2238/1995; } \\
\text { 100/1996; } \\
\text { 0208/1996; } \\
\text { 0717/1996; } \\
0777 / 1996 ; \\
0900 / 1996\end{array}$ & $\begin{array}{l}\text { Alteración } \\
\text { del orden } \\
\text { público, } \\
\text { asesinato de } \\
\text { candidato } \\
\text { presidencial } \\
\text { Alvaro } \\
\text { Gómez } \\
\text { Hurtado }\end{array}$ & $\begin{array}{l}\text { Sentencia C-027/1995 en } \\
\text { parte constitucional y en } \\
\text { parte inconstitucional en lo } \\
\text { atiniente a la muerte de } \\
\text { Alvaro Gómez Hurtado } \\
\text { Sent. C-153/1996 } \\
\text { Constitucional } \\
\text { Sent. C-328/1996 } \\
\text { Constitucional }\end{array}$ & $\begin{array}{l}\text { Se toman } \\
\text { medidas para } \\
\text { los delitos de } \\
\text { omisión, de } \\
\text { denuncia, } \\
\text { interceptación } \\
\text { de } \\
\text { comunicacione } \\
\text { s, inspección } \\
\text { de domicilio, } \\
\text { procedimiento } \\
\text { s de capturas, y } \\
\text { reserva de } \\
\text { identidad del } \\
\text { denunciante. }\end{array}$ & $\begin{array}{l}\text { Se limita la libertad } \\
\text { de expresión, } \\
\text { comunicación y de } \\
\text { prensa, además la } \\
\text { libertad de } \\
\text { locomoción y el } \\
\text { debido proceso }\end{array}$ & $\begin{array}{l}90 \text { días } \\
90 \text { días } \\
90 \text { días }\end{array}$ \\
\hline
\end{tabular}




\begin{tabular}{|c|c|c|c|c|c|c|c|}
\hline $\begin{array}{l}\text { Andrés } \\
\text { Pastrana } \\
(1998-2002)\end{array}$ & $\begin{array}{l}\text { No se declaró } \\
\text { el estado de } \\
\text { conmoción } \\
\text { interior }\end{array}$ & & & & & & 0 días \\
\hline \multirow[t]{2}{*}{$\begin{array}{l}\text { Álvaro } \\
\text { Uribe Velez } \\
(2002-2010)\end{array}$} & $\begin{array}{l}\text { Sexta } \\
\text { declaratoria } \\
\text { Decreto } \\
1837 / 2002 \\
1^{\circ} \text { Prórroga } \\
\text { Dcto. } 2555 \text { de } \\
20022^{\circ} \\
\text { Prórroga Dcto. } \\
245 \text { de } 2003\end{array}$ & $\begin{array}{l}\text { Decretos } 1838 / 2002 \text {, } \\
2002 / 2002, \\
2255 / 2002, \\
1838 / 2002\end{array}$ & $\begin{array}{l}\text { Ataques } \\
\text { guerrilleros y } \\
\text { amenazas a } \\
\text { los alcaldes y } \\
\text { a los } \\
\text { gobernadore } \\
\text { s, e } \\
\text { incremento } \\
\text { general de la } \\
\text { violencia }\end{array}$ & $\begin{array}{l}\text { Sentencia C-802/2002 } \\
\text { Constitucional } \\
\text { Sent. C-063/2003 } \\
\text { Constitutucional } \\
\text { Sent. C-327/2003 } \\
\text { Inconstitucional }\end{array}$ & $\begin{array}{l}\text { Por medio del } \\
\text { decreto } \\
2002 / 2002 \text { se } \\
\text { crean las } \\
\text { Zonas de } \\
\text { Rehabilitación } \\
\text { y } \\
\text { Consolidación, } \\
\text { otorgándole } \\
\text { amplias } \\
\text { facultades } \\
\text { a las fuerzas } \\
\text { judiciales }\end{array}$ & $\begin{array}{l}\text { Propiedad privada, } \\
\text { intimidad, libertad } \\
\text { de } \\
\text { locomoción, } \\
\text { libertad personal, } \\
\text { debido } \\
\text { proceso }\end{array}$ & $\begin{array}{l}90 \text { días } \\
90 \text { días }\end{array}$ \\
\hline & $\begin{array}{l}\text { Séptima } \\
\text { declaratoria } \\
\text { Decreto } \\
3929 / 2008\end{array}$ & & $\begin{array}{l}\text { Paro en la } \\
\text { rama judicial } \\
\text { en el que } \\
\text { participaron } \\
42.000 \\
\text { empleados y } \\
\text { se prolongó } \\
\text { durante } 40 \\
\text { días }\end{array}$ & $\begin{array}{l}\text { Sentencia C-070/2009 } \\
\text { Inconstitucional }\end{array}$ & & & 0 días \\
\hline $\begin{array}{l}\text { Juan Manuel } \\
\text { Santos } \\
(2010-2018)\end{array}$ & $\begin{array}{l}\text { No se declaró } \\
\text { el estado de } \\
\text { conmoción } \\
\text { interior }\end{array}$ & & & & & & 0 días \\
\hline $\begin{array}{l}\text { Iván } \\
\text { Duque } \\
\text { Márquez } \\
(2010-2018) \\
(2018-2022)\end{array}$ & $\begin{array}{l}\text { No se declaró } \\
\text { el estado de } \\
\text { conmoción } \\
\text { interior }\end{array}$ & & & & & & 0 días \\
\hline
\end{tabular}

Por todo lo anterior, y tal como lo muestra la tabla en Colombia ha habido un giro copernicano en el uso de los poderes excepcionales por parte del Gobierno, desde que se introdujo el control integral de los estados de excepción. En consecuencia, y para finalizar este escrito, es necesario hacer una alusión corta al test de proporcionalidad en sentido estricto, que usa la Corte Constitucional para revisar la constitucionalidad de los decretos legislativos, que son producto del estado de conmoción interior. En resumidas cuentas, la Corte Constitucional revisa los decretos legislativos a partir de la utilización de tres presupuestos: el presupuesto fáctico, el presupuesto valorativo y el juicio de suficiencia sobre los medios ordinarios que tiene el Estado para conjurar la crisis, los cuales serán analizados a continuación. 
En primer lugar, indicó el supuesto fáctico que da lugar a la declaratoria y lo circunscribió a una perturbación del orden público que, según señala la Corte, parte de la ocurrencia de hechos concretos, perceptibles y, en consecuencia, verificables, que objetivamente generan una alteración de las condiciones de seguridad y tranquilidad requeridas para el ejercicio de los derechos; en segundo lugar, sometió ese supuesto de hecho a una especial valoración, en cuanto señaló que la perturbación del orden público debía ser grave y que debía tener la virtualidad de atentar de manera inminente contra la estabilidad institucional, la seguridad del Estado o la convivencia ciudadana, en otras palabras, se trata de una valoración relacionada con la intensidad de la perturbación y con sus consecuencias. De un lado, no es cualquier perturbación del orden público, sino una perturbación de naturaleza "grave", que atente y ponga en riesgo esos ámbitos de protección. Finalmente, en tercer lugar, la Corte Constitucional también sujetó ese supuesto de hecho a un juicio sobre la suficiencia de los medios en cuanto precisó que esa grave perturbación no puede ser conjurada mediante el uso de las atribuciones ordinarias de las autoridades de policía69.

En suma, se trata, de un presupuesto fáctico, que es objeto de valoración presidencial y que está sometido a un juicio de suficiencia sobre los medios policivos ordinarios. Conforme a ello, la declaratoria del estado de conmoción interior es legítima si los hechos generadores son verificados, si de ellos se ha inferido, razonablemente, tanto la grave perturbación del orden público como la intensidad exigida y si es cierto que tal perturbación solo puede conjurase acudiendo a medidas extraordinarias.

No obstante, además del control material del decreto que declara el estado de conmoción interior, la Constitución somete la declaratoria al cumplimiento de los requisitos formales que se encuentran consagrados en su artículo $213^{70}$, el cual al determinar el alcance de las facultades conferidas al presidente, señala que ellas serán "las estrictamente necesarias para conjurar las causas de la perturbación e impedir la extensión de sus efectos". Y luego dispone que los decretos legislativos "solamente podrán referirse a materias que tengan relación directa y específica con la situación que hubiere determinado la declaratoria del estado de excepción" (artículo 213 Constitución Política). Estas exigencias se conocen como principios de necesidad y

\footnotetext{
${ }^{69}$ Corte Constitucional, Sentencia C-802 de 2002.

70 Antes de realizar el control material, lo primero que deberá revisar la Corte Constitucional es que formalmente los decretos legislativos cumplan con los siguientes requisitos, ellos son ${ }^{70}: 1$ ) La expedición de un decreto que debe ser suscrito por el Presidente de la República y todos los Ministros; 2) Debe tratarse de un decreto motivado; 3) Debe indicarse si la declaratoria se hace en todo el territorio nacional o en una parte de él; 4) La declaratoria del estado de conmoción interior debe ser por un término no superior a 90 días, prorrogable hasta por dos períodos iguales, el segundo de los cuales requiere concepto previo y favorable del Senado de la República (art. 213 C. P.). De esta manera se realiza el control formal.
} 
especificidad ${ }^{71}$. Así las cosas, una vez que la Corte encuentra que los decretos declaratorios cumplen a cabalidad con los requisitos formales constitucionales y legales, podrá llevar a cabo el examen de los presupuestos materiales de la declaración del estado de conmoción interior, de conformidad con el test de proporcionalidad en sentido estricto.

Para enfrentar la mayor crisis sanitaria mundial de los últimos 100 años, el gobierno colombiano decidió usar competencias dadas por el Código de Policía. Con medidas ordinarias se restringieron derechos fundamentales como las libertades de movilización, reunión, culto, protesta social, se cerraron establecimientos públicos y se impusieron miles de comparendos a quienes infringían estas normas, vulnerando en muchos casos la presunción de inocencia y el debido proceso. También se declararon dos estados de emergencia, durante dos periodos de 30 días cada uno. El Gobierno estuvo facultado para expedir decretos legislativos y dicha competencia fue usada sobre todo para tomar medidas económicas. Nótese que para limitar derechos fundamentales se usaron medidas ordinarias y para temas económicos se usaron medidas extraordinarias. Una crisis sanitaria sin precedentes, como la generada por el COVID19, ha generado una crisis institucional, también, sin precedentes en el sistema de checks and balances de la estructura del Estado colombiano. El control político a cargo del Congreso de la República y los controles jurisdiccionales presentaron fallas evidentes. Hoy solo resta restablecer la eficacia de los límites y controles y así preservar al Estado Constitucional de Derecho $^{72}$.

\section{Conclusiones}

La figura del estado de conmoción interior, surgió como un mecanismo necesario que puede utilizar el Ejecutivo cuando no puede responder por mecanismos de la normalidad a las "crisis" o "alteraciones" que ponen en peligro "el orden público, la estabilidad o la seguridad de la nación" (art. 213 C. P.), otorgándole amplias facultades al Gobierno y en algunos países incluso la posibilidad de suspender el ordenamiento jurídico y la propia Constitución, de manera temporal, hasta que se pudiera restablecer el equilibrio y el orden jurídico que se ha roto.

No obstante, la legislación de urgencia en la actualidad, en lugar de ser una solución o una forma adecuada para enfrentar las crisis a las cuales se somete el Estado, se convierte en un

${ }^{71}$ Tobón (2016), pp. 151-152.

72 Mendieta y Tobón (2020), pp. 243. 
mecanismo que despoja a los ciudadanos de sus garantías y derechos fundamentales, porque la anormalidad o la excepcionalidad en las democracias occidentales, y más aún en las democracias latinoamericanas, se ha convertido en una "costumbre normal", pues las personas conviven con la excepcionalidad como si fuese parte de la normalidad, como si fuese un puzzle en el "paisaje cotidiano", olvidando que el Congreso, y el proceso legislativo son la mayor fuente de legitimidad del Estado social y democrático de derecho.

En todo caso, lo más importante de este artículo, es resaltar que en Colombia el estado de conmoción interior, no se declara constitucional desde el año 2002, porque si bien el presidente Álvaro Uribe Vélez intentó realizar una declaratoria del mismo en el año 2009, esta fue considerada inexequible, demostrando que el Gobierno ha preferido hacerle frente a las crisis o situaciones de "anormalidad" utilizando los mecanismos de la "normalidad", pruebas de ello son el acuerdo de paz celebrado en el año 2016 entre el Gobierno Colombiano y las FARC, o enfrentando la pandemia del COVID-19 de manera simultánea, con medidas ordinarias y la declaratoria de dos estados de emergencia. Sin duda alguna, en Colombia existe un flamante triunfo sobre el uso de la conmoción interior, y el control constitucional que realiza la Corte Constitucional a los decretos legislativos, se ha convertido en un límite infranqueable para el poder Ejecutivo.

No obstante, y a pesar de que pretendemos resaltar en este ensayo el papel protagónico de la Corte Constitucional en la protección de los derechos y garantías ciudadanas durante los estados de excepción en Colombia, también somos conscientes de los riesgos que se generan en la democracia, si se pretende que los jueces sean los únicos que garanticen el Estado constitucional y democrático de derecho. En efecto, si la judicialización se torna excesiva, pone en tela de juicio los propios principios democráticos.

\section{Bibliografía citada}

Agamben, Giorgio (2005): Homo Sacer II. Estado de excepción, Traducción de Flavia Costa e Ivana Costa, (Buenos Aires, Adriana Hidalgo editora).

Barreto Rozo, Antonio (2012): “La generación del estado de sitio: el juicio a la anormalidad institucional en la Asamblea Nacional Constituyente de 1991", en Precedente: Revista Jurídica (Vol. 1), pp. 9-48. 
Bedoya, Andrés Felipe y Vásquez, David Alberto (2015): “Proceso de paz colombiano en prensa y revistas: un análisis desde la aproximación histórica discursiva y la argumentación pragmadialéctica", en Revista Virtual Universidad Católica del Norte (№ 44), pp. 81-101.

Camargo, Pedro Pablo (1996): Los estados de excepción en Colombia: análisis del proyecto del gobierno (Bogotá, Ediciones J. Radar). (2008): Los estados de excepción en Colombia. 3a ed. (Bogotá: Leyer).

Camargo, Ricardo (2010): “Constitucionalismo y la regla de derecho: el problema del universalismo y la transgresión”, en Estudios Constitucionales (Vol. 8, № 2), pp. 31-48.

Cepeda Espinosa, Manuel José (1985): Estado de sitio y emergencia económica, (Bogotá: Contraloría General de República).

Echeverri Duque, Sebastián (2014): “Los estados de excepción en Colombia: un estudio de caso", en CES Derecho (Vol. 5, № 1), pp. 6-17.

García, Diego (1987): Estados de emergencia en la Región Andina (Lima, Comisión Andina de Juristas).

García, Mauricio (2001): “Constitucionalismo perverso: normalidad y anormalidad constitucional (1957-1997)”, en: B. Sousa y M. García (dirs.). El caleidoscopio de las justicias en Colombia (Bogotá, Uniandes, Siglo del Hombre, Colciencias, CES) pp. 317-370.

García Márquez, Gabriel (1998): Los funerales de la mamá grande (Bogotá, Norma).

García Villegas, Mauricio y Uprimny, Rodrigo (2005): "¿Controlando la excepcionalidad permanente en Colombia? Una defensa prudente del control judicial de los estados de excepción". [Disponible en https://bit.ly/3gpCD1o].

(2009): El control judicial de los Estados de excepción en Colombia. (Bogotá, Centro de Estudios de Derecho, Justicia y Sociedad).

Girón Reguera, Emilia y Revenga Sánchez, Miguel (2005): “La Corte Constitucional colombiana ante las medidas de seguridad y defensa nacional del gobierno de Uribe", en Revista de Estudios Políticos (№ 127), pp. 99-127. 
Iturralde, Manuel (2005): "Estado de derecho vs. estado de emergencia: los estados de excepción y la construcción de la temporalidad del derecho en Colombia", en Bonilla, Daniel e Iturralde, Manuel, Hacia un nuevo derecho constitucional, (Bogotá, Universidad de los Andes), pp. 83-151.

Justiniano Robledo, Federico (2010): “Las garantías judiciales como vías de tutela de los derechos fundamentales en estados de emergencia" (in) Constitucional, en Estudios Constitucionales, (Vol. 8, № 2), pp. 247-292.

Loewenstein, Karl (1976): Teoría de la Constitución. 2a. ed. (Barcelona: Ariel).

Mendieta, David (2018): "El (des)control de constitucionalidad en Colombia”, en Estudios Constitucionales (Año 16, № 2), pp. 51-88.

Mendieta, David (2019): “A Crise da Democracia e do Sistema de Freios e Contrapesos nos Estados Unidos". En Luiz Arcaro y Roberto Dias (eds.), Crise das Democracias Liberais (Río de Janeiro, Editora Lumen Juris), pp. 220-243.

Mendieta, David y Tobón, Mary Luz (2020): “La pequeña dictadura del covid-19 en Colombia: uso y abuso de normas ordinarias y excepcionales para enfrentar la pandemia". Revista Opinión Jurídica. Vol. 19, número 40, pp. 243-259.

Norrie, Alan William y Páez Rojas, Gustavo José (2015): La justicia en la mesa de sacrificios de la historia: la culpa de la guerra en Arendt y Jaspers (Bogotá, Universidad Libre).

Reales, Clara (2007): “El control de los decretos declaratorios de los estados de excepción”, en J. Cepeda; E. Montealegre y J. Alexei (eds.), Teoría constitucional y políticas públicas: bases críticas para una discusión. (Bogotá, Universidad Externado de Colombia), pp. 615-713.

Ríos Álvarez, Lautaro (2009): “Defensa judicial de los derechos humanos en los estados de excepción”, en Estudios Constitucionales (Vol. 7, № 1), pp. 277-296.

Rosatti, Horacio Daniel (2004): “Un círculo vicioso: impacto de las emergencias continuadas en el diseño institucional de Argentina. Emergencia y división de poderes", en Revista Latinoamericana de Derecho (№ 1), pp. 449-471. 
Schmitt, Carl (1999): La dictadura: desde los comienzos del pensamiento moderno de la soberanía hasta la lucha de clases proletarias (Madrid, Alianza).

Silva Irarrázaval, Luis Alejandro (2018): “El control judicial de los estados de excepción constitucional: la supremacía del Presidente de la República”, en Revista Chilena de Derecho, (Vol. 45, № 1), pp. 81-103.

Tobón Tobón, Mary Luz (2011): “Suspensión de garantías: la muerte tibia de la Constitución Política de Colombia de 1991", en Pensamiento Jurídico, (№ 32), pp. 61-97.

(2016): "La conmoción interior: el juicio de constitucionalidad a la luz de la Constitución Política de Colombia de 1991”, en Prolegómenos (Vol. 19, № 38), pp. 145-160.

(2019): Los estados de excepción: imposibilidad de suspensión de los derechos humanos y las libertades fundamentales (Bogotá, Grupo Editorial Ibáñez).

Tobón Tobón, Mary Luz y Mendieta González, David (2017): “Los estados de excepción en el régimen constitucional colombiano", en Opinión Jurídica, (Vol. 16, № 31), pp. 67-88.

Valencia, Hernando (1997), Cartas de batalla: una crítica al constitucionalismo colombiano, 2a. ed. (Bogotá, Fondo Editorial CEREC).

Viridiana Molinares, Hassan (2013): “Guerra irregular y Constitución: garantismo judicial de la Corte Constitucional colombiana", en Cuestiones constitucionales, (№ 29), pp. 245-283.

\section{Normas jurídicas citadas}

Congreso de la República de Colombia. (1994). Ley 137 de 1997 por medio de la cual se regulan los estados de excepción en Colombia. Diario Oficial No. 41.379, de junio 3. Bogotá, Colombia.

Corte Constitucional de Colombia, Sentencia C-004. M. P. Eduardo Cifuentes Muñoz, 7 de mayo de 1992.

Corte Constitucional de Colombia, Sentencia C-556. M. P. Ponencia conjunta, 15 de octubre de 2002. 
Corte Constitucional de Colombia, Sentencia C-231. M. P. Eduardo Cifuentes Muñoz, 29 de julio de 1993.

Corte Constitucional de Colombia, Sentencia C-300. M. P. Eduardo Cifuentes Muñoz, de julio 1 de 1994.

Corte Constitucional de Colombia, Sentencia C-466. M. P. Carlos Gaviria Díaz, 18 de octubre de 1995.

Corte Constitucional de Colombia, Sentencia C-027. M. P. Hernando Herrera Vergara, 29 de enero de 1996.

Corte Constitucional de Colombia, Sentencia C-565. M. P. José Gregorio Hernández Galindo, 6 de noviembre 1996.

Corte Constitucional de Colombia, Sentencia C-802. M. P. Jaime Córdoba Triviño, 2 de octubre de 2002.

Corte Constitucional de Colombia, Sentencia C-070. M. P. Clara Elena Reales Gutiérrez, 12 de febrero de 2009.

Corte Constitucional de Colombia, Sentencia C-216. M. P. Juan Carlos Henao Pérez, 29 de marzo de 2011.

Corte Suprema de Justicia, Sala Plena. Sentencia del 15 de octubre de 1974. M. P. José Gabriel de la Vega y Eustorgio Sarria. 